\title{
Preface: Blasts from the past and back to the future
}

\author{
11th International Symposium on Cladocera
}

\author{
Linda C. Weiss $\cdot$ Eric von Elert $\cdot$ Christian Laforsch
}

Published online: 11 November 2019

(C) Springer Nature Switzerland AG 2019

Following the kind invitation of the organizers Christian Laforsch and Max Rabus, the 11th International Symposium on Cladocera gathered scientists from all over the world working on multi-disciplinary aspects of Cladoceran biology. The meeting is renowned to house Cladoceran research from multiple disciplines including evolutionary history, host-parasite and predator-prey interactions, phylogeny, environmental genomics, population genetics, biogeography, systematics, and taxonomy.

First being held in 1986 in Hungary, this meeting recurs every 3 years. The 11 th meeting was held in Kulmbach, Germany, from September the 24th to the 29th, 2017, in the wonderful Plassenburg Castle in the

Guest editors: Linda C. Weiss, Eric von Elert, Christian Laforsch \& Max Rabus / Proceedings of the 11th International Symposium on Cladocera

L. C. Weiss ( $\square)$

Department of Animal Ecology, Evolution and Biodiversity, Ruhr-Universität Bochum, Bochum, Germany

e-mail: linda.weiss@rub.de

E. von Elert

Aquatic Chemical Ecology, Institute for Zoology, University of Cologne, Cologne, Germany

C. Laforsch

Animal Ecology I, University of Bayreuth, Bayreuth, Germany margravial city of Kulmbach, Germany. During this 1 week, scientists from all around the globe coming from Austria, Belarus, Belgium, Brazil, China, Czechia, Germany, India, Norway, Mexico, Poland, Switzerland, Russia, Thailand, and the USA came to Kulmbach and presented 45 talks and 31 posters on Cladocera biology. The diversity of contributions provided new insights, perspectives, and advances to the multiple facets of Cladocera research. Following the tradition, this meeting was again organized in one session providing each participant with the opportunity to follow and discuss the breadth of the field. Long and fruitful discussions on recent results were held throughout the poster session accompanied by assorted craft beer typical for this region of Franconia.

As keynote speaker, Dieter Ebert (University of Basel) presented exciting insights into the "diversity panel" which is a collection of clones from $>170$ populations of Eurasia, Africa, and North America. Using this panel, Dieter Ebert travels in geographic space and demonstrates genetic and phenotypic divergence of diverse traits, including patterns of local adaptation in Daphnia magna (Yampolsky et al., 2013; Fields et al., 2015; Lange et al., 2015; Roulin et al., 2016). Ralph Tollrian (Ruhr-University Bochum) presented in his keynote novel insights into the field of predator induced phenotypic plasticity in the model system Daphnia, which is among the most striking examples of this phenomenon. Yet, not only did Ralph Tollrian show how Daphnia perceives and 
interprets environmental cues predicting predation pressure (Weiss et al. 2015a, b, 2016, 2018) but he also presented remarkable data on the biomechanical properties of morphological defenses and how these render Daphnia less susceptible to different predators (Kruppert et al., 2016, 2017, 2019).

These conference proceedings offer an overview over the whole diversity of research that was presented at the symposium. As species of the order Cladoceran comprise a group of small crustaceans inhabiting freshwater bodies world wide, they have been and still are popular models for freshwater ecology research. Particularly, many Cladocerans are able to respond promptly to environmental changes and are very sensitive to environmental contaminants such as pharmaceuticals and microplastics (Rivetti et al., 2016; Imhof et al., 2017). In addition, they occupy a central position in food webs as being a trophic link and serving as the major natural food source for fishes and other predatory invertebrates. Especially, Daphnia is known for its ability to convert phytoplankton biomass into animal biomass, and extensive research in recent decades has indicated that the availability of essential lipids in seston is key to Daphnia fitness, e.g., thermal tolerance during diel vertical migration (DVM) (Müller-Navarra, 2008; Brzeziński \& von Elert, 2015). Werner et al. here show that body content of polyunsaturated fatty acids (PUFAs) varied among a $D$. magna population and was negatively correlated with heat tolerance. This variation in PUFA content is hypothesized to affect fish-induced diel vertical migration amplitudes (Werner et al., 2018). Fink \& Windisch detail differential gene expression involved in the physiological pathways associated with the nutritionally highly important omega-3 PUFAs (Fink $\&$ Windisch, 2018). The authors demonstrate that the dietary availability of the omega-3 PUFA EPA affects the expression of some previously investigated genes that were almost exclusively dependent on omega-6 PUFAs. This supports the understudied idea that there is an EPA-dependent eicosanoid pathway in $D$. magna, which has repercussions for our understanding of the biochemical physiology of this essential dietary compound and its role for zooplankton nutrition.

Cladocerans have a short generation cycle, and the transparent carapace allows, e.g., easy observation of offspring in the maternal brood pouch. Moreover, many Cladocerans can switch between clonal and sexual reproduction, so that under favorable conditions, organisms reproduce clonally thereby effectively increasing population size of environmentally adapted phenotypes. The deterioration of environmental conditions induces sexual reproduction and thus genetic diversity. Sexually produced embryos are genetically encoded to go through a state of suspended animation. Encapsulated in a protective shell, the ephippium, these embryos accumulate season-byseason in the sediments. We can use these dormant egg banks to travel back in time and interrogate several decades-old populations upon resurrection (Weider et al., 2018). Complemented by long-term environmental data and Next-generation Sequencing strategies, we may obtain insights into the involved eco-evolutionary processes like adaptation, hybridization, introgression, speciation, and gene flow. In fact, it is possible to link candidate genome regions to selection pressures resulting from, e.g., stressors such as predation, parasitism, or toxins released during cyanobacteria blooms. Genomic approaches are now also rounded up by proteomic analysis in order to obtain a more comprehensive understanding of the associated molecular pathways (Otte et al., 2018).

But not only can we use Cladocerans to travel with them in time and space; some Cladocerans now boldly go where no Cladocera has gone before; i.e., to space, as they are promising candidates for bioregenerative life support systems as presented by Miriam Knie and Christian Laforsch (Knie et al., 2018). Other contributions covered aspects of taxonomy, diversity, predation, food quality, physiology, stress, and eco-evo interactions; more molecular-orientated topics were population genetics and omics approaches.

It will be interesting to see the further developments in the field at the 12th Cladoceran Symposium, which will be organized by Piet Spaak and Adam Petrussek in Verbania, Italy, right next to the beautiful Largo Maggiore from October 4, 2020, to October 10, 2020. This will be a special occasion as it will be a Joint Meeting of the Cladocera symposium and the Daphnia Genomics Consortium.

\section{References}

Brzeziński, T. \& E. von Elert, 2015. Predator evasion in zooplankton is suppressed by polyunsaturated fatty acid limitation. Oecologia 179: 687-697. 
Fields, P. D., C. Reisser, M. Dukic, C. R. Haag \& D. Ebert, 2015. Genes mirror geography in Daphnia magna. Molecular Ecology 24: 4521-4536.

Fink, P. \& H. S. Windisch, 2018. The essential omega-3 fatty acid EPA affects expression of genes involved in the metabolism of omega-6-derived eicosanoids in Daphnia magna. Hydrobiologia. https://doi.org/10.1007/s10750018-3675-z.

Imhof, H. K., J. Rusek, M. Thiel, J. Wolinska \& C. Laforsch, 2017. Do microplastic particles affect Daphnia magna at the morphological, life history and molecular level? PLoS ONE. https://doi.org/10.1371/journal.pone.0187590.

Knie, M., B. W. Ribeiro, J. Fischer, B. Schmitz, K. Van Damme, R. Hemmersbach, D.-P. Häder \& C. Laforsch, 2018. Approaches to assess the suitability of zooplankton for bioregenerative life support systems into space—a journey of how humans adapt and live in microgravity. https://doi. org/10.5772/intechopen.74261.

Kruppert, S., L. Deussen, L. C. Weiss, M. Horstmann, J. O. Wolff, T. Kleinteich, S. N. Gorb \& R. Tollrian, 2019. Zooplankters' nightmare: the fast and efficient catching basket of larval phantom midges (Diptera: Chaoborus). PLoS ONE. https://doi.org/10.1371/journal.pone.0214013.

Kruppert, S., M. Horstmann, L. C. Weiss, C. F. Schaber, S. N. Gorb \& R. Tollrian, 2016. Push or pull? The lightweight architecture of the Daphnia pulex carapace is adapted to withstand tension, not compression. Journal of Morphology 277: 1320-1328.

Kruppert, S., M. Horstmann, L. C. Weiss, U. Witzel, C. F. Schaber, S. N. Gorb \& R. Tollrian, 2017. Biomechanical properties of predator-induced body armour in the freshwater crustacean Daphnia. Scientific Reports 7: 9750.

Lange, B., A. P. Kaufmann \& D. Ebert, 2015. Genetic, ecological and geographic covariables explaining host range and specificity of a microsporidian parasite. Journal of Animal Ecology 84: 1711-1719.

Müller-Navarra, D. C., 2008. Food web paradigms: the biochemical view on trophic interactions. International Review of Hydrobiology. https://doi.org/10.1002/iroh. 200711046.

Otte, K. A., C. Effertz, T. Fröhlich, G. J. Arnold, C. Laforsch \& E. von Elert, 2018. Proteomic analysis in the model organism Daphnia has the potential to unravel molecular pathways involved in phenotypic changes in response to changing environmental conditions. Hydrobiologia. https://doi.org/10.1007/s10750-018-3718-5.
Rivetti, C., B. Campos \& C. Barata, 2016. Low environmental levels of neuro-active pharmaceuticals alter phototactic behaviour and reproduction in Daphnia magna. Aquatic Toxicology. https://doi.org/10.1016/j.aquatox.2015.07. 019.

Roulin, A. C., Y. Bourgeois, U. Stiefel, J. C. Walser \& D. Ebert, 2016. A photoreceptor contributes to the natural variation of diapause induction in Daphnia magna. Molecular Biology and Evolution 33: 3194-3204.

Weider, L. J., P. D. Jeyasingh \& D. Frisch, 2018. Evolutionary aspects of resurrection ecology: progress, scope, and applications-an overview. Evolutionary Applications 11: 3-10.

Weiss, L. C., B. Albada, S. M. Becker, S. W. Meckelmann, J. Klein, M. Meyer, O. J. Schmitz, U. Sommer, M. Leo, J. Zagermann, N. Metzler-Nolte \& R. Tollrian, 2018. Identification of Chaoborus kairomone chemicals that induce defences in Daphnia. Nature Chemical Biology 14: 1133-1139.

Weiss, L. C., E. Heilgenberg, L. Deussen, S. M. Becker, S. Kruppert \& R. Tollrian, 2016. Onset of kairomone sensitivity and the development of inducible morphological defenses in Daphnia pulex. Hydrobiologia 779: 135-145.

Weiss, L. C., F. Leese, C. Laforsch \& R. Tollrian, 2015a. Dopamine is a key regulator in the signalling pathway underlying predator-induced defences in Daphnia. Proceedings of the Royal Society B 282: 1-9.

Weiss, L. C., J. Leimann \& R. Tollrian, 2015b. Predator-induced defences in Daphnia longicephala: location of kairomone receptors and timeline of sensitive phases to trait formation. Journal of Experimental Biology 218: 2918-2926.

Werner, C., M. Ilic \& E. von Elert, 2018. Differences in heat tolerance within a Daphnia magna population: the significance of body PUFA content. Hydrobiologia. https://doi. org/10.1007/s10750-018-3769-7.

Yampolsky, L. Y., T. M. M. Schaer \& D. Ebert, 2013. Adaptive phenotypic plasticity and local adaptation for temperature tolerance in freshwater zooplankton. Proceedings of the Royal Society B: Biological Sciences 281: 20132744.

Publisher's Note Springer Nature remains neutral with regard to jurisdictional claims in published maps and institutional affiliations. 